\title{
Neonatal congenital syphilis Diagnosis by the absorbed fluorescent treponemal antibody (IgM) test
}

\author{
N. A. JOHNSTON \\ From the V.D. Reference Laboratory (P.H.L.S.), The London Hospital, London, E.1
}

It is known that foetal antibodies produced in response to intrauterine infections occur mainly in the IgM fraction of cord and neonatal sera, whereas passively transferred maternal antibodies are found exclusively in the IgG fraction (Gitlin, Kumate, Urrusti, and Morales, 1964; Alford, 1965). Indirect fluorescent antibody techniques have been established for the early detection of IgM class antibody in congenital toxoplasmosis, rubella, and cytomegalovirus infections (Remington, Miller, and Brownlee, 1968; Hanshaw, Steinfield, and White, 1968; Cohen, Ducharme, Carpenter, and Deibel, 1968). The total serum IgM levels are also commonly elevated in infants with neonatal infections (McCracken and Shinefield, 1965; Stiehm, Amman, and Cherry, 1966; Alford, Schaefer, Blankenship, Straumfjord, and Cassady, 1967).

In congenital syphilis, the production of intrauterine antitreponemal antibody was investigated by Silverstein and Lukes (1962). Serological tests designed to diagnose or exclude congenital syphilis have been described by many authors (Scotti and Logan, 1968; Scotti, Logan, and Caldwell, 1969; Alford, Polt, Cassady, Straumfjord, and Remington, 1969; Sepetjian, Guerraz, Monier, Nivelon, and Thivolet, 1970; Mamunes, Cave, Budell, Anderson, and Steward, 1970). All these workers used a modified fluorescent treponemal antibody (FTA) technique demonstrating IgM class antitreponemal antibody. There is general agreement that the presence of IgM antitreponemal antibody in the newborn infant's serum suggests that congenital infection has occurred. Alford and others (1969) observed that a positive FTA IgM test plus raised total serum IgM regularly preceded other changes in congenital syphilis of late onset.

In the present study a modified fluorescent treponemal antibody absorption (FTA-ABS) test detecting only specific antitreponemal IgM class antibody was used in addition to conventional tests (STS) to examine sera from neonates.

Received for publication July 14, 1972

\section{Clinical material}

520 specimens of serum were obtained from 205 infants born to mothers with a history of untreated or treated syphilis. As a control group an additional thirty specimens were examined from healthy infants born to mothers who were serologically non-reactive. Specimens were collected through the co-operation of physicians in the United Kingdom and overseas. It was requested that paired specimens from both mother and baby should be sent together with relevant clinical details. Only those infants were included in the congenital syphilis group whose sera did not contain iso-agglutinins, since the presence of these is presumptive evidence of transplacental leakage (Franklin and Kunkel, 1958). Four cases were excluded from the series because of the presence of ABO agglutinins in the neonatal period. Treated cases were re-tested at regular intervals during the follow-up period which averaged 6 to 12 months.

\section{Race of 25 infants with congenital syphilis}

Eighteen of these infants were born in the United Kingdom; twelve had mothers born in this country, one a mother from Mexico, and five mothers from the Caribbean area. The other seven infants had been born overseas; three in Australia (two of whom were Aborigines), three in South Africa, and one in Bermuda.

Nine of these 25 babies were offered for adoption.

\section{Methods and reagents}

CONVENTIONAL TESTS (STS)

Reiter protein (RPCFT), cardiolipin Wassermann reaction (CWR), and VDRL (slide) tests were performed by the methods described by Wilkinson (1969).

FTA-ABS PROCEDURE

All sera were examined quantitatively. The FTA-ABS technique was that described by the Venereal Disease Research Laboratory (1968), except that an ultrasonicate of Reiter treponemes was used instead of sorbent for the removal of group antitreponemal antibody. Serial 3-fold dilutions of serum in sonicate were prepared. Duplicate estimations were performed using monospecific conjugates for IgG and IgM; these were obtained from Wellcome 
Reagents Ltd. Control titrations were included in each batch of tests, using aliquots of positive and negative stock reference sera stored at $-20^{\circ} \mathrm{C}$. Control sera were tested against both $T$. pallidum and Reiter treponemes to confirm removal of group antibody.

\section{ANTIGEN}

$T$. pallidum (Nichols strain) suspensions freshly prepared in the laboratory were used. Particular care was necessary in selecting antigens for use in the FTA-ABS IgM procedure, because many batches of treponemes acceptable for the FTA-ABS IgG system appeared to be deficient in antigenicity for the IgM system. Each new treponemal suspension was assayed by titration with control reference sera before use.

\section{Results}

Quantitative FTA-ABS IgG and IgM tests were carried out on the $\mathbf{5 2 0}$ specimens of serum from 205 newborn infants referred for serological diagnosis, and specimens from thirty healthy babies whose mothers were serologically non-reactive were examined as negative controls. In the latter group conventional standard tests (STS) and FTA-ABS IgG and IgM results were all negative.

\section{(1) PASSIVE TRANSFERENCE OF ANTIBODY}

In 180 infants ( 365 sera) the immunological pattern obtained was FTA-ABS IgG positive and IgM negative. The FTA-ABS titre of mother and baby was usually the same. As a rule the VDRL titre of the baby was the same or less than the maternal titre. These untreated infants were observed over a followup period averaging 5 months (Fig. 1) and the antibody levels rapidly declined. None of this group developed clinical signs of infection, and each was followed until the antitreponemal tests became negative.

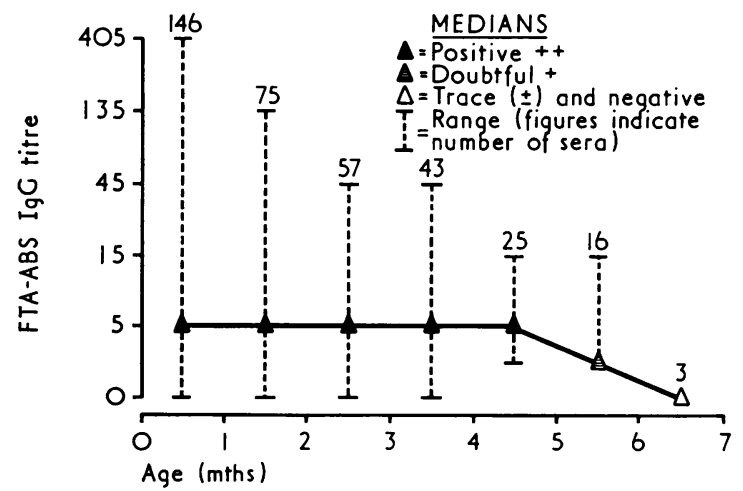

FIG. 1 Passive transfer of maternal antibodies. Median and range of FTA-ABS IgG titres of 365 sera
In this group of 180 infants none had a positive FTA-ABS IgM result, but in nineteen cases the initial readings were FTA-ABS IgG positive $(++)$ and FTA-ABS IgM trace $(t)$. Fourteen mothers of these nineteen infants had received treatment in the latter half of pregnancy. Second specimens from the infants tested within 4 to 6 weeks gave negative FTA-ABS IgM results, and negative observations were obtained at regular intervals during a 5-month follow-up. No antibiotic therapy was given to this group as it was presumed that these cases represented partial or successful treatment in utero. Careful observation was maintained to detect any fluctuation in antibody titres.

Correlation of serological and clinical findings in this series of 180 babies confirmed that the initially positive results obtained on the infant sera were due to maternal antibodies. None developed clinical or serological evidence of syphilis.

\section{(2) NEONATAL CONGENITAL SYPHILIS}

In 25 neonates (155 sera) the FTA-ABS IgG and IgM results were both positive or became positive. Nine babies showed signs of infection at birth or within 4 weeks; six of these had a positive FTA-ABS IgM test and in three it was doubtful. Of sixteen babies without signs at birth, six showed a delayed onset of evidence of infection, three of whom were from two pairs of twins (the fourth twin was a macerated still-birth); initially the VDRL was nonreactive in four of the six.

Of all the mothers only three had received any treatment during pregnancy, and in two of these the treatment was judged to be inadequate.

A comparison of the VDRL results on serum from both mother and baby was possible in eighteen of the 25 infected infants. In five the VDRL titre of the baby was greater than the maternal titre by either one or two tube dilutions; four of these infants showed clinical evidence of disease. In the remaining thirteen infants the VDRL titre was the same or less than the maternal titre.

An examination of the first specimen gave a positive FTA-ABS IgM test in sixteen of these 25 infants; the test was doubtful in three and negative in six. FTA-ABS IgG tests were positive in 24 of the 25 infected infants. In ten cases the FTA-ABS IgM results were positive in the absence of any clinical evidence of disease, and immediate therapy was given.

\section{(a) Acute infection}

When acute infection was diagnosed at or soon after birth, the response to treatment was immediate, as illustrated by the case shown in Fig. 4 (overleaf), 


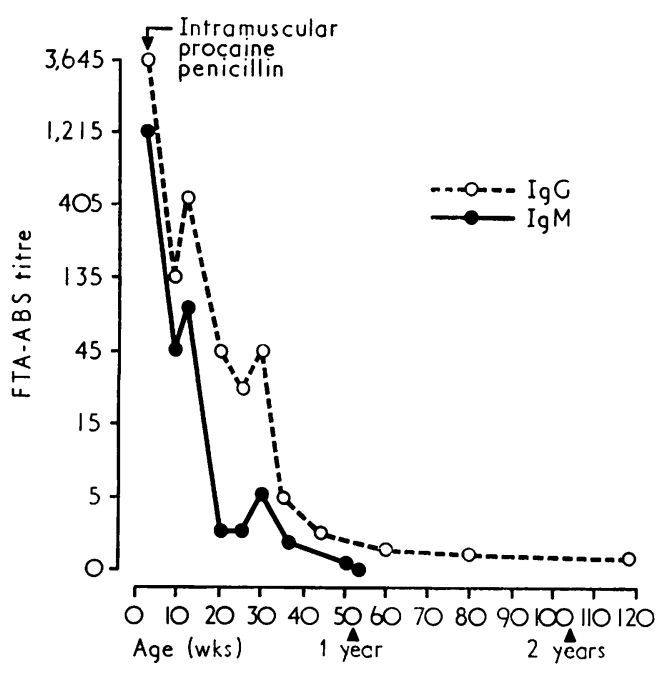

FIG. 2 Congenital syphilis. Acute infection diagnosed and treated immediately after birth FTA-ABS. IgG and IgM titres. Follow-up period 2 years

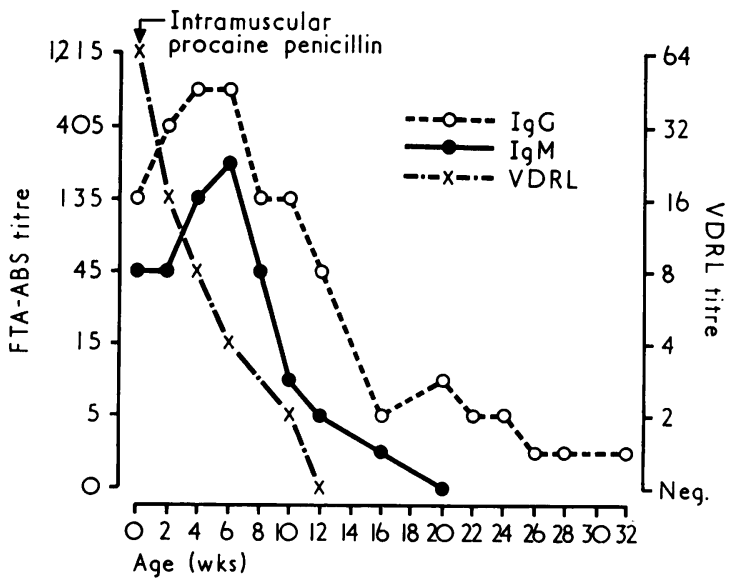

FIG. 4 Congenital syphilis. Immediate response to intramuscular procaine penicillin therapy.

$V D R L$ and FTA-ABS IgG and IgM titres.

Follow-up period 8 months

which shows a sudden fall in VDRL antibody and a rapid decline in the level of $\operatorname{IgM}$ antibody. Although FTA-ABS IgG levels were relatively higher after successful therapy, all antibody levels rapidly decreased. However, low levels of FTA-ABS IgG and occasionally traces of IgM persisted for long periods. For two infants the observation period extended as long as 2 to 3 years (Figs 2 and 3), but the average length of follow-up in treated cases was 6 to 12 months (Figs 5 and 6, opposite).

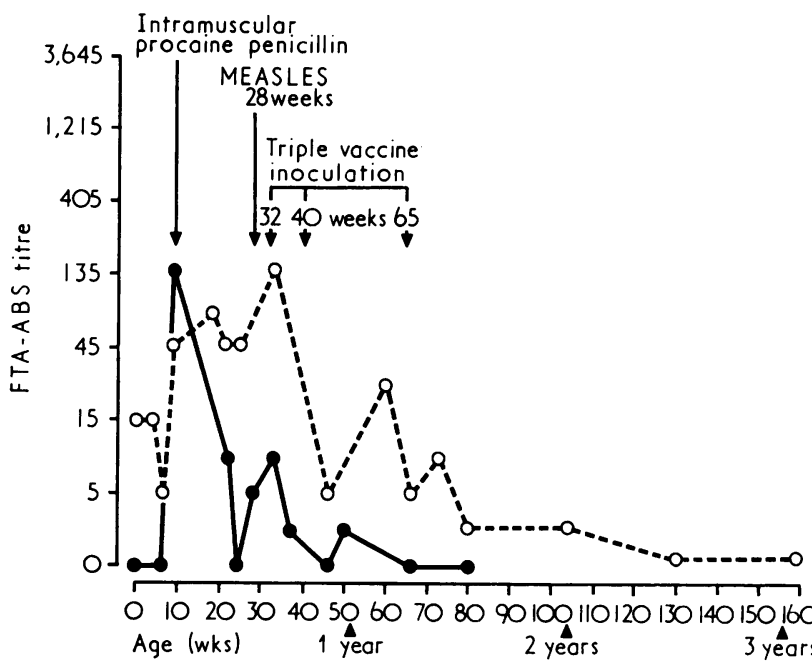

FIG. 3 Congenital syphilis. Delayed onset of infection, treated at 9 weeks.

FTA-ABS IgG and IgM titres. Follow-up period 3 years

(b) Infection of delayed onset

In six infants the onset of evidence of infection was delayed; the initial FTA-ABS IgG test done at birth or within 4 weeks was positive in five, and negative in one (Table I). The initial FTA-ABS IgM test was negative in all six, but 5 to 9 weeks after birth positive antitreponemal IgM fluorescence, ranging from $1+$ to $4+$, was obtained in all of them. Five of the infants developed clinical evidence of infection. A typical pattern of the results in these cases (Fig. 3) shows a greater fluctuation in antibody levels after treatment than was seen in the cases of acute infection which received early treatment (Fig. 2).

\section{Case reports}

(1) One infant encountered in this series typifies the clinical picture of delayed onset of infection; the serial data obtained are shown in Table II and Fig. 3. In this newborn baby, apparently healthy and without symptoms, the detection of $\operatorname{IgM}$ antitreponemal antibodies was delayed until 9 weeks after birth. The mother was unmarried, had had no antenatal care, and was diagnosed as a case of early secondary syphilis after delivery (Maternal STS on delivery: RPCFT ++ , VDRL R4, CWR ++ , FTA-ABS + +).

The first three specimens collected from the baby showed some decline in titre consistent with a pattern of passively transferred antibody during the first 6 weeks after birth. At 9 weeks there was a dramatic increase in antibody levels (Table II). Within 2 weeks clinical signs 


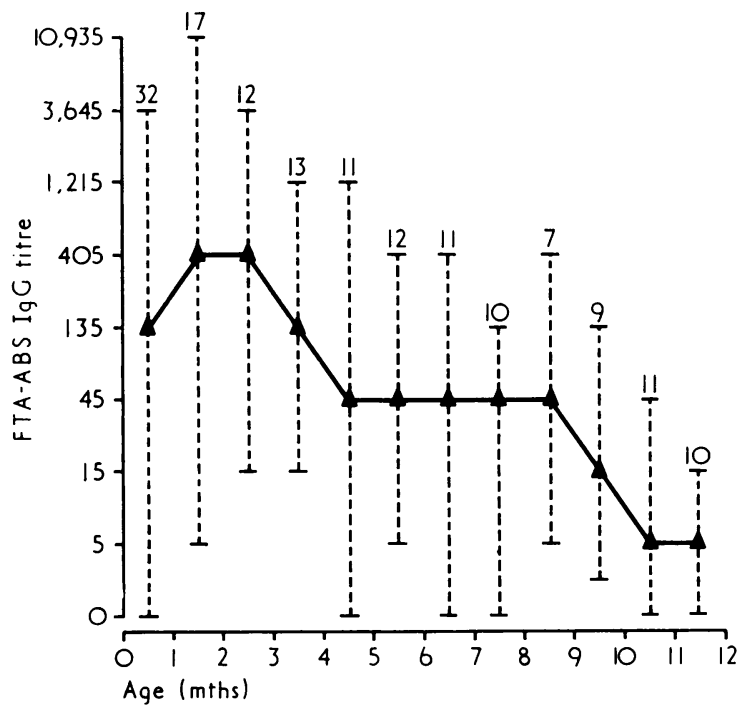

FIG. 5 Congenital syphilis.

Median and range of FTA-ABS IgG titres on 155 sera. Follow-up period 12 months

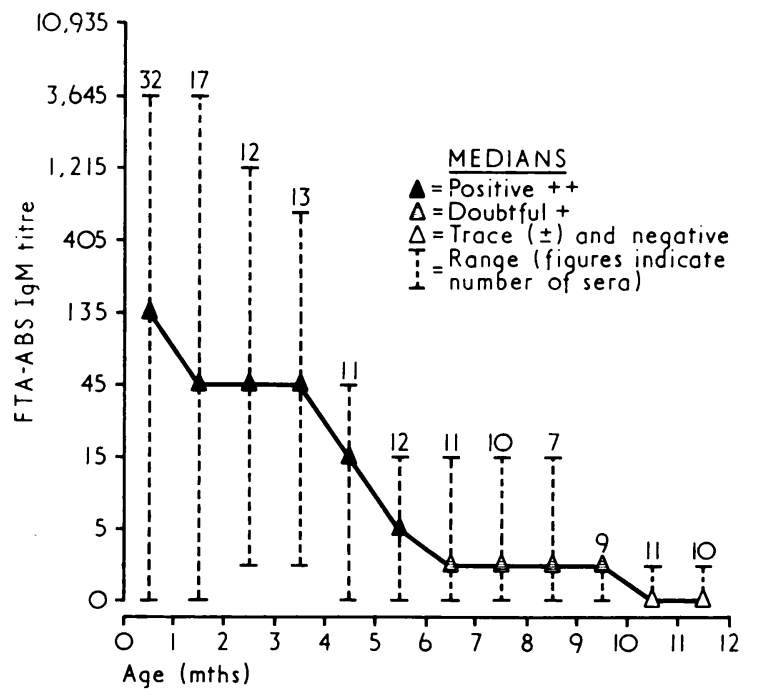

FIG 6 Congenital syphilis.

Median and range of FTA-ABS IgM titres on 155 sera. Follow-up period 12 months

TABLE I Results of serial tests in a case of congenital syphilis of delayed onset (Case 2)

\begin{tabular}{|c|c|c|c|c|c|c|}
\hline Specimen no. & Age (wks) & \multicolumn{3}{|l|}{ Tests } & \multicolumn{2}{|c|}{$F T A-A B S \quad$ titres } \\
\hline 1 & 1 & - & - & - & - & - \\
\hline 3 & 5 & $\cdot$ & R8 & $\cdot 4$ & $T+405$ & $+\quad 135$ \\
\hline
\end{tabular}

TABLE II Serial tests in one case of congenital syphilis of delayed onset (Case 1)

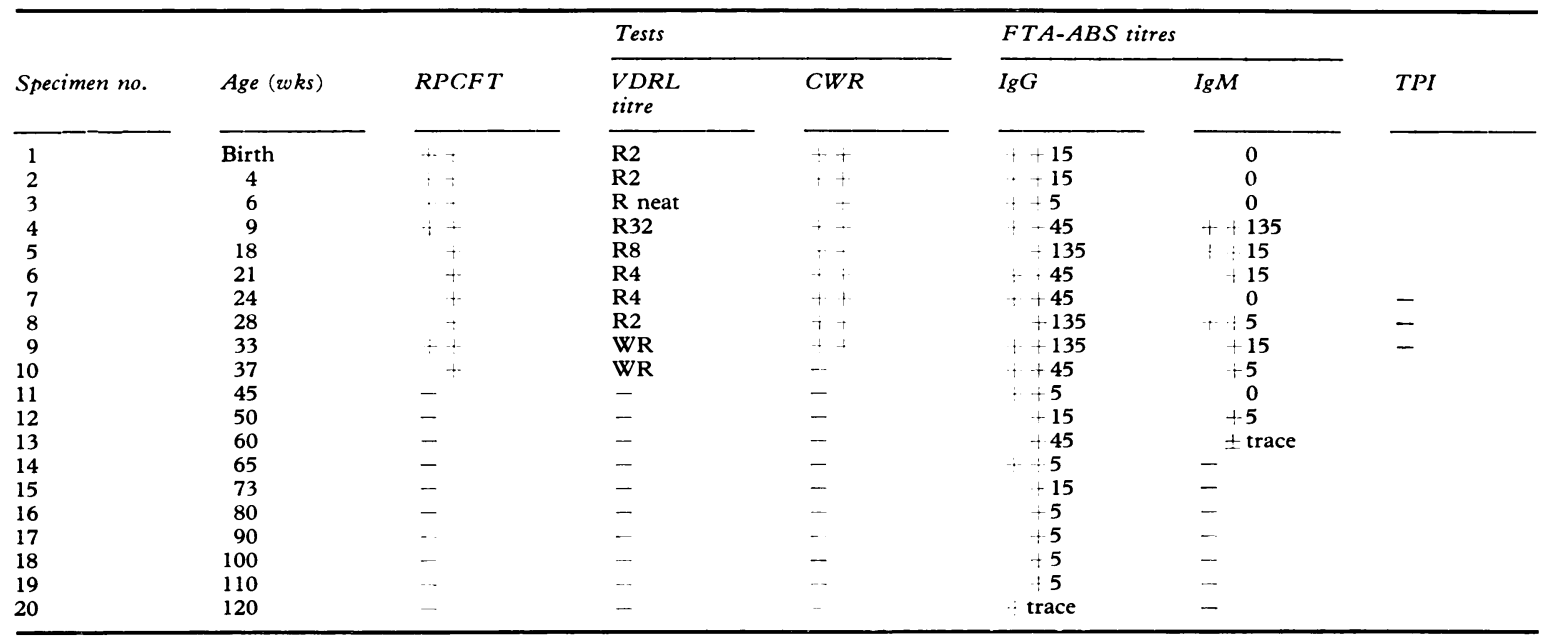

++ Positive +Doubtful - Negative R Reactive WR Weakly reactive 
of congenital syphilis became apparent including hepatosplenomegaly and anaemia. Radiography showed evidence of syphilitic osteitis. Penicillin therapy was given, and blood samples were taken at approximately monthly intervals; the serological pattern of results is illustrated in Table II and Fig. 3. The response to therapy was fairly rapid apart from fluctuations in titre during the observation period.

(2) Serum from another baby without signs at birth was negative in all serological tests for syphilis, including FTA-ABS IgG and IgM, on two specimens examined during the first and second weeks. A third specimen at 5 weeks gave positive results (Table I).

The mother had acquired syphilis from the father, probably during the last month of pregnancy. Antenatal tests had been negative but, on delivery, the VDRL test was reactive at a titre of 1 in 2 ; and a later specimen showed RPCFT + +, VDRL R4, CWR + +, FTA-ABS ++ .

The father was treated for secondary syphilis 2 weeks after the birth of the baby. $X$ rays of the infant's skull and long bones showed no evidence of osteitis. Treatment was given, a 10-month follow-up was uneventful, and no clinical signs of congenital syphilis developed.

(3) In contrast a third infant, whose mother had been treated when 6 months pregnant because of positive serological tests, was delivered prematurely at 35 weeks and had clinical signs of advanced congenital syphilis. FTA-ABS IgG and IgM tests were positive at low titres, and after treatment with penicillin were followed by elevation and then decline in antibody levels similar to those shown in Fig. 3.

\section{Discussion}

Syphilis is perhaps the oldest and best example of an infection which, if contracted in utero, may cause serious disease which can be prevented by specific treatment if recognized in time. The immunological data presented in this study agree with those already cited by other investigators, and show that the FTA-ABS IgM test is a sensitive and specific screening test for congenital syphilis. It enabled the differentiation between the passive transfer of maternal antibodies in 180 infants and the presence of congenital syphilis in 25, either symptomatic or asymptomatic.

Our knowledge of placental function in the pregnant woman is very incomplete. In animals extensive investigations have shown that all possessors of a yolk-sac system fully transmit immunoglobulins (Brambell, Hemming', Henderson, Parry, and Rowlands, 1949; Kulangara and Schechtman, 1962), but there are differences between species which affect the process of selection. The ultrastructural and molecular aspects of the transference mechanism are complex, but the preliminary step appears to consist of active uptake of maternal proteins by the cells of the yolk sac, or the placenta, through the mechanism of pinocytosis (Davies, 1958; Hemmings, 1956, 1958). Full transmission must be a matter of cellular function rather than one of histological arrangement. It is probable that incompetence of foetal lymphoid cells may be affected by the nature of the environment in which they operate and that deficiency of antibody production in the newborn is partly a reflection of the presence of high levels of transmitted maternal antibodies (Butler, Barr, and Glenny, 1954); only after birth is the newborn released from this inhibitory 'blanketing' effect.

In the present study an important finding was that IgM antibody was not present at birth in six out of 25 infants who were finally diagnosed as having congenital syphilis. One baby whose mother was infected late in pregnancy had neither IgG nor IgM reacting antibody until 5 weeks after birth. Examination of the maternal records revealed that in three other cases in which IgM antibody was not detected in the baby's serum at birth, infection of the mother had probably occurred around the 7th month of pregnancy (two received treatment then but this was judged as inadequate); IgM antitreponemal antibody was not detectable in these children until 5 to 9 weeks after birth.

When the mother has been treated during pregnancy, a problem of interpretation of trace levels of IgM antitreponemal antibodies in the newborn baby may arise. There were nineteen infants in this category and regular blood sampling to detect changes in the antibody titre was essential. The interpretation of results is not straightforward and requires a trained observer, critical control of reagents, and skilled laboratory procedure.

\section{Summary}

Quantitative FTA-ABS IgG and IgM tests were performed on 520 specimens of serum from 205 neonates born to mothers with a history of treated or untreated syphilis.

An additional thirty specimens from healthy babies born to mothers with negative tests were included; all these infants had negative FTA-ABS IgG and IgM tests.

Passive transference of maternal antibodies was found in 180 infants and the presence of congenital syphilis was confirmed in 25 .

In six infants evidence of infection was delayed until 5 to 9 weeks after birth; it is emphasized that in all six the FTA-ABS IgM test was negative at birth. In contrast ten infants without signs at birth were diagnosed as having congenital syphilis on serological grounds alone. 
It is considered that, when congenital syphilis is a possibility, follow-up of the infants for at least 3 months is essential before infection can be excluded. Nevertheless, although detection of an immunogical response may be delayed, the FTA-ABS IgM test is undoubtedly of great value in the diagnosis of congenital syphilis in neonates.

I wish to thank Dr. A. E. Wilkinson and Dr. P. O'Neill for reading the manuscript and for encouragement and helpful advice. My thanks are due to Dr. B. Dodds for assistance with the $\mathrm{ABO}$ agglutinin tests, and to Mr. H. G. Ferguson for the diagrams. I am grateful to the clinicians who sent specimens and for their co-operation throughout the series, and to the London Hospital Research Fund for financial support.

\section{References}

Alford, C. A., Jr. (1965) Amer. F. Dis. Child., 110, 455 , Polt, S. S., Cassady, G. E., Straumfjord, J. V., and Remington, J. S. (1969) New Engl. F. Med., 280, 1086

—, Schaefer, J., Blankenship, W. J., Straumfjord, J. V., and CASSADY, G. E. (1967) Ibid., 277, 437

Brambell, F. W. R., Hemmings, W. A., HeNderson, M., Parry, H. J., and Rowlands, W. T. (1949) Proc. roy. Soc. (Lond.), Ser. B., 136, 131

Butler, N. R., BARR, M., and GlenNy, A. T. (1954) Brit. med. F., 1, 476

Cohen, S. M., Ducharme, C. P., Carpenter, C. A., and DeIBEL, R. (1968) f. Lab. clin. Med., 72, 760

DaviEs, J. (1958) In Gestation, Transactions of the Fourth Conference, Princeton, N.J., 1957, p. 163. Josiah Macy Jr. Foundation, New York

FrankiIN, E. C., and KuNKel, H. G. (1958) F. Lab. clin. Med., 52, 724

Gitlin, D., Kumate, J., Urrusti, J., and Morales, C. (1964) f. clin. Invest., 43, 1938

Hanshaw, J. B., Steinfeld, H. J., and White, C. J. (1968) New Engl. F. Med., 279, 566

Hemmings, W. A. (1956) Proc. Roy. Soc. (Lond.), Ser. B., 145,186

- (1958) Ibid., Ser. B., 148, 76

Kulangara, A. C., and Schechtman, A. M. (1962) Amer. F. Physiol., 203, 1071

Mamunes, P., Cave, V. G., Budell, J. W., Anderson, J. A., and Steward, R. E. (1970) Amer. F. Dis. Child., 120, 17
MCCracken, G. H., and Shinefield, H. R. (1965) Pediatrics, 36, 933

Remington, J. S., Miller, M. J., and Brownlee, I. (1968) Ibid., 41. 1082

Scotti, A. T., and Logan, L. (1968) \}. Pediat., 73, 242

,-- , and Caldwell, J. G. (1969) Ibid., 75, 1129

Sepetjian, M., Guerraz, F. T., Monier, J. C., Nivelon, J. L., and Thivolet, J. (1970) Brit. f. vener. Dis., 46, 18

SilverSTEIN, A. M., and LUKES, R. J. (1962) Lab. Invest., 11, 918

Stirhm, E. R., Ammann, A. J., and Cherry, J. D. (1966) New Engl. F. Med., 275, 971

VENEREAL DiseAse RESEARCH LABORATORY (Atlanta, Georgia) (1968) Hlth Lab. Sci., 5, 23

WILKINSON, A. E. (1969) 'Serological Tests for Syphilis'. Association of Clinical Pathologists Broadsheet No. 41

Syphilis congénitale néo-natale. Diagnostic par le test de l'anticorps tréponémique fluorescent absorbé (IgM)

SOMMAIRE

Des tests quantitatifs FTA-ABS (IgG et IgM) ont été effectués sur 520 sérums provenant de 205 nouveau-nés, nés de mères ayant des antécédents de syphilis traitée ou non traitée.

Un autre groupe de trente spécimens provenant d'enfants sains nés de mère à tests négatifs fut ajouté; tous ces enfants avaient un FTA-ABS (IgG et IgM) négatif.

On observa la transmission passive des anticorps maternels pour 180 enfants et l'existence d'une syphilis congénitale fut confirmée pour 25 .

Chez six enfants, l'infection ne fut prouvée que 5 à 9 semaines après la naissance; il est souligné que pour tous les six, le test FTA-ABS IgM était négatif à la naissance. Par contre, on diagnostiqua sur les éléments sérologiques seuls une syphilis congénitale chez 10 enfants ne présentant pas de signes à la naissance.

On considère que, lorsque la syphilis congénitale est possible, il est essentiel de suivre les enfants au moins 3 mois avant d'exclure l'infection. Toujours est-il, quoique la réponse immunologique puisse être retardée, que le test FTA-ABS-IgM est indubitablement de grande valeur pour le diagnostic de la syphilis congénitale néo-natale. 